\title{
Consequences of intimate partner violence against pregnant women and the involvement of health care providers
}

\author{
Elena Madalina DUMITRESCU ${ }^{1}$, Valeriu GHEORMAN ${ }^{1}$, Anca PATRASCU ${ }^{1}$, \\ Ileana Octavia PETRESCU2, Victor GHEORMAN ${ }^{3}$ \\ ${ }^{1}$ Faculty of Nursing and Midwifery, University of Medicine and Pharmacy, Craiova, Romania \\ ${ }^{2}$ Department of Pediatrics, Faculty of Medicine, University of Medicine and Pharmacy, Craiova, Romania \\ ${ }^{3}$ Doctoral School, University of Medicine and Pharmacy of Craiova, Craiova, Romania
}

\begin{abstract}
Background. Violence against women is a major public health problem. Violence against pregnant women has serious health consequences for both pregnant women and child.

Purpose. Using an online search on Pubmed our aim was to make a review of consequences of intimate partner violence against women, emphasizing the size of the impacts on pregnant women, pregnancy and child and aspects of the involvement of health providers.

Method. The following key words have been on Pubmed introduced: "intimate partner violence", "violence against women", "pregnant women", "pregnancy outcomes", "prenatal care". We reviewed research with a high evidence level published in the last five years, using the Pubmed, Cochrane database as well as WHO and EU documents until August 2016.

Results. Most women are reluctant to reveal the phenomenon, but there are some who would consider acceptable for doctors to systematically ask about violence if the patient has certain injuries or features. Prenatal care is an opportunity for early identification and prevention of recurrence of such violence against women.

Conclusion. The consequences of intimate partner violence against women pregnant are important and serious consequences on both short and long term health of the woman and the child. Health professionals should be prepared formal urgently to recognize situations that might be caused or complicated by IPV and how to react in these situations.
\end{abstract}

Keywords: intimate partner violence; violence against women; pregnant women; pregnancy outcomes; prenatal care

\section{INTRODUCTION}

Violence against women is any act of gender-based violence that results in, or is likely to result in, physical, sexual or mental suffering to women, including threats of such acts, coercion or arbitrary deprivation of liberty, whether in public or in private life (1). This is accepted as a major public health problem with major physi- cal, mental, sexual and reproductive health consequences and is now widely recognized as an abuse, a violation of human rights.

Intimate partner violence (IPV) is a behaviour within a framework of intimate relationship that causes physical, sexual or psychological harm to those in relationship, including acts of physical aggression, sexual coercion, psychological abuse and control behaviours $(1,2)$. 
Intimate partner violence and sexual violence are included among the most common forms of violence against women (2).

Evidence gathered following the survey on violence against women conducted by the European Union Agency for Fundamental Rights (FRA UE) shows that most women who are victims of violence do not report their experiences neither to police nor any victim support organizations (3). While some European Union (EU) member states and research institutions have conducted investigations and other research on violence against women, within the EU remains a lack of comprehensive data and comparable information in this area.

Data presented by World Health Organization (WHO) in "Global status report on violence prevention 2014" show that women who experienced intimate partner violence are more likely to use health services (more visits to health care providers, longer hospitalization) than those who did not go through such experiences (1), although they rarely disclosed explicitly violence as a basic reason.

The report of the European Union Agency for Fundamental Rights shows the results of the most comprehensive surveys at EU level for which over 42,000 women from all 28 EU countries were interviewed face to face about women's experiences related to violence. The document published data on violence during pregnancy so that: among the women who have suffered violence inflicted by a partner previously and who were pregnant during that relationship, $42 \%$ had experienced violence from that partner during pregnancy compared with $20 \%$ each they were subjected to violence by current partner. Although insufficiently explored differences could reflect that women are less willing to disclose current partner violence when questioned. However, FRA UE survey shows that " $87 \%$ of women would consider acceptable for doctors to systematically put questions about violence if the patient has certain lesions or characteristics" (3). The results of this survey showed that abused women are more likely willing to consult or be in contact with health services than any other professional organization or agency (3). In Romania, only $79 \%$ of respondents believe that health care Eurobarometer can provide help in cases of domestic violence compared to 93\% European average (4).

The World Health Organization has expressed deep concern that violence against women during pregnancy has serious conse- quences on the health of both of it, such as miscarriage and premature birth, child's low birth weight, recognizing the opportunity prenatal care provides for early identification and prevention of recurrence of such violence $(5,6)$.

Romania has health providers dealing with pregnant women, offering prenatal care. In the first prenatal care guideline for family doctors published in Romania "prenatal care are interventions designed to ensure optimal development of pregnancy consist of screening, prevention and counseling are offered to pregnant women. They are essential to capture early every circumstance that might affect pregnancy outcomes Otherwise that they can be treated and monitored. Any intervention must be proved effective and acceptable for pregnant women" (7).

In this paper, we reviewed research with a high evidence level published in the last five years, using the Pubmed, Cochrane database as well as WHO and EU documents until August 2016 related to intimate partner violence against women, emphasizing the size of the impacts on pregnant women, pregnancy and child and aspects of the involvement of health providers in order to urge intensification of attention interventions, formal training and Romanian research on this field. When the high evidence did not respond to search questions, we accepted an the lower evidence level.

\section{Epidemiology}

Research conducted in North America, Europe and other regions cited by WHO documents have shown a high prevalence of violence against women. Globally it was found that 38\% of crimes committed against women were perpetrated by their intimate partner (8). Thus, 13$61 \%$ of women reported they had been abused at least once in their life by intimate partner; 6-59\% reported forced sexual intercourse or such attempt by an intimate partner at least once in life, and between $1 \%$ and $28 \%$ reported being physically abused during pregnancy by their partner (2).

Some studies have shown that domestic violence/intimate partner violence and car accidents are prevalent causes of trauma reported in pregnancy (9). In countries of the Organisation for Economic Co-operation and Development (OECD) prevalence data varies, depending on the tool design and applied studies. Most studies underestimate the prevalence of violence during pregnancy, suggesting an underestimation of the problem in some countries, ad- 
ditional studies are needed (10). In Japan, maternal exposure to verbal and physical violence during pregnancy was reported by $10.9 \%$, or $1.2 \%$ of women (11). A meta-analysis of risk factors for domestic violence published by James L. et al. in 2013 showed that the prevalence of emotional abuse was $28.4 \%, 13.8 \%$ physical abuse, sexual abuse $8 \%$, and abuse before pregnancy and low level of education were found to be strong predictors of abuse during pregnancy (12).

Data about the situation in Romania resulting from the investigation FRA UE (2014) shows that physical violence and/or sexual violence against women starting at 15 years was $24 \%$, a figure which exceeds the European average (22\%) when analyzed violence exercised by current partner or previous and held below the European average ( $14 \%$ vs. $22 \%$ ) when it comes to violence exercised by someone other than their partner. In European level, only 33\% of partner's victims contacted police or other organizations after the worst incident of violence, and for a quarter of the victims, the reason they did not report the worst act of violence upon them by their partner or another person was that they were feeling ashamed or embarrassed about what happened. Regarding psychological violence within the couple (the most common forms being found disdain or humiliation of women by a partner in a private setting), one out of three women suffered abusive psychologically from current or previous partner (3).

\section{Consequences of partner violence on pregnant woman}

Exposure to partner violence during pregnancy can lead to adverse birth outcomes, both directly and indirectly. Of women physically or sexually assaulted by a partner, $42 \%$ had experienced damage as a result of this violence, have more health problems or risk behaviours, have a risk $16 \%$ more likely to have a baby with low weight at susceptiblitate birth and 2 times more likely to have an induced abortion or to experience depression. In some countries, these women were 1.5 times more likely to acquire HIV and 1.6 times to have syphilis. Direct abdominal blows or sexual abuse were associated with complications of pregnancy, such as placental injury, uterine contractions, premature rupture of membranes and genitourinary infections. Abuse may also lead to an increase in behavioural risk factors associated with adverse birth outcomes such as maternal smoking, alco- hol or drugs, inadequate prenatal care or insufficient increase in weight in the prenatal period $(1,8)$.

There are studies that have shown that women who are abused tend to have higher levels of stress, less support from their partners and low self esteem. These factors can facilitate the indirect biological mechanisms that contribute to negative birth outcomes (13). Women who experience partner violence are more likely to have an unwanted pregnancy (14). Studies in Latin America and Asia regions showed that the probability of having an unwanted pregnancy was 2 times higher in abused women than in those not abused (15).

Partner violence was associated with abortion (16) and serious consequences of miscarriage or premature births and babies born with low birth weight $(5,13,17)$.

A systematic review in 2014 showed that women exposed to verbal violence had a significant probability to abuse their offspring (11).

Lifetime exposure to partner violence and predominantly partner violence is associated with stress-related sleep disturbances and poor quality of sleep during pregnancy (18).

\section{Involvement of health providers}

There is data reported by WHO which shows that professionals consider intimate partner violence a criminal justice problem, dealing with it as a marital issue and are unprepared to cope with this situation because medical education deals little or no with this phenomenon (2). There is evidence that health professionals are unsure how to respond to intimate partner violence. However, considering the safety of mother and child were motivated to identify intimate partner violence. Responsive to identifying intimate partner violence in prenatal care providers need training to know how to intervene in the future safe in the care of abused women (19). Evidence cited by Stover, John et al. in "Interventions to Improve Reproductive Health" published in 2016 in Reproductive, Maternal, Newborn and Child Health suggests that early intervention has a positive impact on future risk behaviours of children and adolescents can contribute to decrease social and economic costs (6).

Health care providers must be able to recognize signs of violence and prevent recurrence of such situations (6). The medical guidelines developed by the Romanian medical societies dealing with prenatal care lack in recommendations regarding violence against pregnant women $(7,20)$. 
IPV screening in health systems can be defined as a systematic routine investigation of all women reporting on their experience intimate partner violence using a set of questions (21).

In general, studies have shown that screening for intimate partner violence increases identification rate of women facing violence, but showed no reduction in partner violence and no notable benefit for women's health (2).

There were cited barriers identified in cases involving medical attention for domestic violence related to the pattern of society, or individual characteristics of the profession and the legal or institutional factors (22). Studies cited by Taft et al. showed barriers to universal screening: health care provider's attitude, lack of recurrent training, lack of adequate referral services and other support, women with partners during the visit (21). However, there is evidence that screening during pregnancy is vital to stop intimate partner violence ongoing and possible adverse outcomes for mother and child (23), and screening for verbal abuse in pregnant women could be an effective approach for identifying mothers with a higher risk of infant abuse (22). WHO published in 2013 situations that may be caused or complicated for IPV: traumatic repeated or explanation implausible, sexually transmitted infections or symptoms genitourinary repeated or unexplained symptoms of depression or anxiety, multiple pregnancies, eating problematic alcohol harming body, suicide (8).

Prenatal care is an opportunity for early identification and prevention of recurrence of violence against women (5), although some interventions may create ethical dilemmas. An authorities announcing intervention type is recommended only after "an enlightening discussion with the victim" and her free consent and the woman must be fully convinced that chose the best way approach (22).

A systematic review of the literature from 2014 shows the lack of substantial evidence on effective interventions for intimate partner violence during the prenatal period and out of its context. However, there are indications that intensive support can improve life quality on short term and reduce physical abuse one to two years after the intervention for women recruited for domestic violence shelters or refuges. Short supportive interventions could provide short-term benefits for mental health and reduce abuse, especially in pregnant women and less severe abuses (24). Other few studies have shown that programs implying visits at home as early as possible after birth and some counseling interventions have produced promising results (significant decrease in physical violence, sexual and psychological partner), but high quality research is required for providing more evidence on the effect of certain interventions and to clarify which interventions should be taken in the context of perinatal care (25).

A systematic review and meta-analysis published in 2016 by Donovan et al., strongly supports the need for effective interventions to prevent violence during pregnancy. Providing effective therapeutic interventions for women who disclose abuse may help prevent adverse birth outcomes and evaluation of programs of support (advocacy) and support is needed for better aid for women after disclosure. Primary prevention as prenatal education by informing couples about the risk of congenital negative results in the exposure to intimate partner violence could help recognize these behaviours and intimidation (13).

Primary care associates licensed (midwives and nurses) medical staff with family doctors should ask about intimate partner violence when women are presented for sexually transmitted infections, menstrual disorders, sexual problems, miscarriages or induced abortions (26).

There are indications that efforts to combine family planning and violence prevention can help reduce unintended pregnancy (15).

There are regulations in force in Romania (27) which determine which state institutions and local communities are to focus on prevention and combating domestic violence. Such centers are organized by the Population Information and Sensitization, shelters for abused persons, maternity centers and others, and systems collaboration with institutions and NGOs. Medical personal resource of accurate information needs to know how they can be called especially knowing that on average, almost onefifth of women in the EU (19\%) are not aware of any of the support services for victims of violence against women in their country, including those listed in the questionnaire (3).

\section{CONCLUSIONS}

Partner violence against women is a public health problem that requires intervention at several levels. Scientific data are insufficient and show differences in prevalence from country to country. The consequences of intimate partner violence against women pregnant are impor- 
tant and serious consequences on both short and long term health of the woman and the child. Health professionals should be prepared formal urgently to recognize situations that might be caused or complicated by IPV and how to react in these situations. We believe that prenatal care is an opportunity for identifying intimate partner violence and early intervention and requires priority approach at several levels.
It should continue research about violence against pregnant women to find the best ways of solving this problem.

Acknowledgements: This research is included in research area "Interventions for maternal and child health" of Faculty of Nursing and Midwifery, University of Medicine and Pharmacy of Craiova

Conflict of interest: none declared Financial support: none declared

\section{REFERENCES}

1. World Health Organization. (2014) "Global status report on violence prevention 2014." World Health Organization

2. World Health Organization. (2013) Responding to intimate partner violence and sexual violence against women: $W H O$ clinical and policy guidelines. World Health Organization, 2013. WHO/RHR/13.10

3. European Union Agency for Fundamental Rights. (2014). Violence against Women: an EU-wide survey. https://fra.europa.eu/sites/ default/files/fra-2014-vaw-survey-mainresults-apr14_en.pdf

4. TNS Opinion \& Social. (2010). Domestic Violence Against Women Report 2010. http://ec.europa.eu/public_opinion/archives/ ebs/ebs_344_en.pdf

5. WHA67, R. (2014). 15. Strengthening the role of the health system in addressing violence, in particular against women and girls, and against children. Sixty-seventh World Health Assembly, Geneva, 19-24

6. Stover J., Hardee K., Ganatra B., \& García C. Interventions to Improve Reproductive Health. Reproductive, Maternal, Newborn, and Child Health, 95, 2016.

7. Popa I., Bunescu D., Condrea A., Picioreanu I., Popescu D.S., Zmeu A. et al. Îngrijiri prenatale de rutinä în sarcina cu risc scäzut. Ghid de practicä pentru medicii de familie. Infomedica. 2005

8. World Health Organization. (2013) Global and regional estimates of violence against women: prevalence and health effects of intimate partner violence and non-partner sexual violence. World Health Organization.

9. Mendez-Figueroa H., Dahlke J.D., Vrees R. A., \& Rouse D.J. Trauma in pregnancy: an updated systematic review. American journal of obstetrics and gynecology, 209 (1), 1-10, 2013

10. Liepe K., \& Blättner B. "[Violence during pregnancy: prevalence studies in OECD countries]." Gesundheitswesen

(Bundesverband der Arzte des Offentlichen Gesundheitsdienstes (Germany)) 75.8-9 (2013): 473-480.

11. Amemiya A., \& Fujiwara T. Association between maternal intimate partner violence victimization during pregnancy and maternal abusive behavior towards infants at 4 months of age in Japan. Child abuse \& neglect, 55, 32-39, 2016

12. James L., Brody D., \& Hamilton Z. Risk factors for domestic violence during pregnancy: a meta-analytic review. Violence and victims, 28(3), 359-380, 2013

13. Donovan B.M., Spracklen C.N., Schweizer, M.L., Ryckman K.K. \& Saftlas A.F. Intimate partner violence during pregnancy and the risk for adverse infant outcomes: a systematic review and meta-analysis. BJOG: An International Journal of Obstetrics \& Gynaecology. DOI: 10.1111/1471-0528.13928, 2016

14. Baird K., Creedy D., \& Mitchell T. Intimate Partner Violence and Pregnancy Intentions: A Qualitative Study. Journal of clinical nursing. DOI: 10.1111/jocn.13394, 2016

15. Cha S., Masho S.W., \& Heh V. Partner violence victimization and unintended pregnancy in Latina and Asian American women: Analysis using structural equation modeling. Women \& health, 1-16, 2016

16. Hall M., Chappell L.C., Parnell B.L., Seed P.T., \& Bewley S. Associations between intimate partner violence and termination of pregnancy: a systematic review and meta-analysis. PLoS Med, 11(1), e1001581, 2014

17. Hill A., Pallitto C., McCleary-Sills J., \& Garcia-Moreno C. A systematic review and meta-analysis of intimate partner violence during pregnancy and selected birth outcomes. International Journal of Gynecology \& Obstetrics, 133(3), 269-276, 2016

18. Sanchez S.E., Islam S., Zhong Q.Y., Gelaye B., \& Williams M.A. Intimate partner violence is associated with stress-related sleep disturbance and poor sleep quality during early pregnancy. PloS one, 11(3), e0152199, 2016

19. Hatcher A.M., Woollett N., Pallitto C.C., Mokoatle K., Stöckl H., \& Garcia-Moreno C. Willing but Not Able Patient and Provider Receptiveness to Addressing Intimate Partner Violence in Johannesburg Antenatal Clinics. Journal of interpersonal violence, 0886260516651094, 2016
20. Ordin Ministerul Sănătății 1524/2009.(2010) Monitorul Oficial, nr. 88 bis

21. Taft A.J., Small R., Humphreys C., Hegarty K., Walter R., Adams C., \& Agius P. Enhanced maternal and child health nurse care for women experiencing intimate partner/family violence: protocol for MOVE, a cluster randomised trial of screening and referral in primary health care. BMC public health, 12(1), 811, 2012

22. Hostiuc S., Curcă C.G., \& Dermengiu D. Consimțământ şi confidențialitate în asistența medicală a femeilor victime ale violenței domestice. Revista Română de Bioetică, 9(1), 37-49, 2011

23. Bianchi A.L., McFarlane J., Cesario S., Symes L., \& Maddoux J. Continued intimate partner violence during pregnancy and after birth and its effect on child functioning. Journal of Obstetric, Gynecologic \& Neonatal Nursing, 45(4), 601-609, 2016

24. Rivas C., Ramsay J., Sadowski L., Davidson L.L., Dunne D., Eldridge S. et al. Advocacy interventions to reduce or eliminate violence and promote the physical and psychosocial well-being of women who experience intimate partner abuse. The Cochrane Library http://onlinelibrary. wiley. com/doi/10.1002/14651858.CD005043. pub3/pdf, 2015

25. Van Parys A.S., Verhamme A., Temmerman M. \& Verstraelen H. Intimate partner violence and pregnancy: A systematic review of interventions. PloS one, 9(1), e85084, 2014

26. Loeffen M.J., Wong S.H.L.F., Wester F.P., Laurant M.G. \& Lagro-Janssen A.L. Are gynaecological and pregnancy-associated conditions in family practice indicators of intimate partner violence? Family practice, 33(4), 354-359, 2016

27. Legea 217/2003. (2014). Monitorul Oficial, Partea I nr. 205. http://www.dreptonline.ro/ legislatie/legea_prevenirii_violentei_familie. php 